\title{
Post-Registration IPL: Becoming a Paediatric Practitioner "Virtually"
}

\author{
—NHS Education for Scotland \& University of Nottingham AHP Paediatric \\ E-Learning Pilot Report
}

\author{
Sarah Westwater-Wood ${ }^{1}$, Jane Reid ${ }^{1}$, Pauline Berine ${ }^{2}$, Grahame Pope ${ }^{3}$ \\ ${ }^{1}$ Division of Physiotherapy Education, University of Nottingham, Nottingham, UK \\ ${ }^{2}$ AHP National Lead for Children and Young People, Scottish Government, Edinburgh, Scotland \\ ${ }^{3}$ Education Projects Manager (AHP), NHS Education for Scotland, Edinburgh, Scotland \\ Email: Sarah.Westwater-Wood@nottingham.ac.uk
}

Received September $10^{\text {th }}$, 2012; revised October $8^{\text {th }}$, 2012; October $24^{\text {th }}$, 2012

\begin{abstract}
Educational solutions for allied health professionals (AHP's) need to stimulate problem-solving skills although AHP's seldom have the opportunity to develop these skills in a paediatric environment prior to registration. Computer aided learning (CAL) has become an established educational option with a growing body of literature detailing positive CAL introduction within HC education across many disciplines. NHS Education for Scotland (NES) scoping exercise identified a paucity of paediatric education at a pre and post registration levels for all Allied Health Professionals (AHP's), except speech and language therapists. The question considered was would a reusable CAL (ReTool) be a useful tool in developing inter-professional learning for AHP's in paediatrics with potential to become a core part of induction for new and aspirant paediatric AHP's allowing flexibility in access (location \& time). A pilot was completed with a group of AHP's (N12). ReTool was evaluated positively by users for usability (88.9\% rated very easy or easy). Working with children and young people requires the ability to work as part of a multigency team and an ability to learn from one another therefore individuals were asked to comment on the IPL opportunity of the project. They rated ReTool positively in facilitating joint working and decision making for IPL (N10).
\end{abstract}

Keywords: Inter-Professional Learning; Reusable Computer Aided Learning

\section{Introduction}

An NHS Education for Scotland (NES) scoping exercise identified a paucity of paediatric education at a pre-registration level for Allied Health Professionals (AHPs), with the exception of speech and language therapists (NES, 2009). It also found that at a post-registration level, AHPs had varied access to education and a stakeholder consultation recognised the need for a core learning resource that could be included at induction. The small numbers and geographical distribution of clinicians makes the delivery of inter-professional learning challenging and the vulnerability of the patient group is problematic in delivering relevant learning opportunities. NES and the Physiotherapy Division at University of Nottingham (UoN) entered into a collaborative venture to identify whether a contextualised Reusable e-Tool (ReTool) developed for undergraduate (UG) physiotherapy education in paediatrics could be used as part of a "virtual" paediatric induction programme for multi professional AHPs. The development and implementation of the ReTool is published elsewhere (Westwater-Wood \& Dennick, 2011).

The ReTool utilises a series of virtual case studies with embedded multimedia and when evaluated with UG physiotherapy students it was rated very highly for problem solving and clinical reasoning skills (Westwater-Wood \& Dennick, 2011). Four separate learning tasks are delivered at weekly intervals to stimulate clinical reasoning and problem solving in small group discussion. It was proposed that ReTool may address some of the issues identified for AHPs new to paediatrics with the potential to become an integral part of the educational framework for AHP paediatric induction in Scotland.

\section{Methodology}

In recruiting AHPs to the pilot it was important to reflect the different settings that AHPs worked in across Scotland. Therefore initial contact was made by NES AHP Education Projects Manager to Paediatric AHP managers \& AHP Directors across urban and rural settings in Scotland via a circular e-mail. They were asked if they would be willing for a member of their staff to participate in the pilot and then to identify potential participants who would then be contacted by NES to give them more information and to ascertain willingness to participate. This method identified 15 AHPs willing to participate in the pilot however due to timing of the pilot and other pressures 3 opted not to be involved.

Twelve AHPs were recruited which included physiotherapists, occupational therapists, speech and language therapists and dieticians from 4 of the territorial health boards across NHS Scotland. Participants included AHPs working in 2 children's hospitals, community paediatrics and there were 2 remote and rural practitioners. It was postulated that it would be beneficial to have a mixture of AHPs who were new to paediatrics and also those who were more experienced, with the notion to op- 
timize varied experiences in supporting AHPs new to paediatrics through the induction period. The participants were allocated to one of three groups and were allocated one of 2 case studies. Two groups were allocated a child with Cerebral Palsy and one group a case of developmental delay. One group comprised participants working in children's hospitals solely and the other 2 groups were a combination of hospital and community to reflect the diverse nature of inter-professional learning and working. The pilot ran for 4 weeks with four separate learning tasks delivered each week via ReTool.

Each week the individual groups are presented with case information some which mimics aspects of real practice. So for example there are multimedia elements such as video and audio. These will only play once thus reproducing a telephone conversation or a time limited history taking session with a patient. Other resources are offered as a selection of 2 out of three items so that the group have to discuss the potential usefulness and reasoning for selecting one over the other. Again an example might be "would you phone the patients school or review the occupational therapists full report", given that in real practice time is pressurised. Participants were also expected to take part in a weekly conference call with other members of their group to discuss their reasoning for the choices and their hypothesis development as they gained more details of the case. These sessions were facilitated by the NES AHP Education Projects Manager (JR).

\section{Inclusion Criteria}

- AHP working in paediatric services for all or part of the time

- Internet access at home (due to the NHS firewall the multimedia components of the resource were not accessible at work)

- Agreement from managers that they could participate in the pilot and would be able to negotiate time to work at home Exclusion Criteria

- AHP not working in paediatric services

- No access to internet other than at work

- No agreement from manager

It is acknowledged that due to the recruitment methods and the inclusion and exclusion criteria there could be an element of bias which precluded other individuals taking part. However, it was deemed that for a pilot study on usability of ReTool that this was acceptable.

As this was a service educational development there was no requirement for ethical approval.

The project was evaluated by users for usability and accessibility via a bespoke questionnaire (open and closed questions) with reflective accounts of learning and semi-structured discussions to explore aspects of inter-professional learning and clinical decision making. The bespoke questionnaire was based upon the previous study (Westwater-Wood \& Dennick, 2011) which had demonstrated basic face validity. In line with the UG version, pilot participants also submitted a report detailing their findings for the case study with an action plan for the referrer. The study findings therefore produced a mixture of qualitative and questionnaire based quantitative data.

The timing for the pilot was opportunistic to avoid ReTool being used by the UG students at the same time and also to fit in with project timescales at NES. Although this might not be ideal it did reflect practice and the difficulties releasing time for education for clinicians.

\section{Results}

A total of 11 of the 12 AHPs recruited to the pilot completed it. The individual who was unable to complete had to submit a concurrent post-graduate assessment related to paediatrics at this time and needed to prioritise this. For some questions only 10 AHPs provided answers.

Ten of the twelve participants completed the bespoke questionnaire. This was delivered online by Questback worldwide (http://www.questback.com/) and eleven of the twelve participants completed reflective accounts. All twelve participants participated in at least one of the semi-structured discussions and one group where all 4 participants took part in each of the weekly sessions; the other groups had one or two missing each time due to annual leave or work pressures.

\section{Demographic Information}

The participants were asked to state how long they had been qualified and how long they had worked in paediatrics and the table outlines this information. One of the participants was moderately new to paediatrics ( 1 - 2 years) but had been quailfied for more than 5 years (Table 1).

The following results are reported in relation to each other to combine into themes the 3 elements:

- Bespoke questionnaire

- Reflective accounts

- Semi-structured discussions

\section{Learning Styles}

Individuals were asked to rank the ways they learnt most effectively. Not unsurprisingly for mainly practical AHPs the majority $70 \%(n=7)$ felt that a practical session was most effective but with the exception of 1 individual no-one ranked a web-based workbook as one of their 3 most effective learning modes. However $83.3 \%(n=5)$ stated that they were confident computer users and would "prefer to access activities via the web rather than a book, journal or library".

This question was free text to allow individuals to express their own thoughts and samples of these are displayed below. However the themes were:

- Different formats of learning; audio, video, text

- Inter-professional Learning

- Learning more about particular conditions Things enjoyed most about ReTool $(n=10)$.

For example:

"I enjoyed interacting with therapists from different professions."

"Very practical application, build a report through using the tool rather than writing an essay."

Table 1.

Duration of post graduate qualitfication and experience.

\begin{tabular}{ccc}
\hline Length of time & $\begin{array}{c}\text { Post Qualification } \\
\%(\mathrm{n}=10)\end{array}$ & $\begin{array}{c}\text { Working in Paediatrics } \\
\%(\mathrm{n}=10)\end{array}$ \\
\hline Less than a year & 0 & 40 \\
1 - 2 years & 10 & 30 \\
2 - 5 years & 70 & 20 \\
More than 5 years & 20 & 10 \\
\hline
\end{tabular}


"It was enjoyable learning in a new and different way."

"Interesting insight into other allied health disciplines" "Excellent resources e.g. video of assessments and telephone conversations."

"Opportunity to talk with others about process"

"Hearing other professionals perspectives on case studies and being forced to think holistically"

"Learning more about CP and reading relevant research articles"

"Good way to work through the thought process of subjective and objective assessment"

It was interesting to note the value individuals placed upon accessing contemporary knowledge via research articles and the benefits they perceived in the opportunity to discuss with colleagues. The impression is given that this is perhaps not common practice and may indicate a need for further education and support.

Things enjoyed least about ReTool $(n=10)$

This question was also free text to allow individuals to express their own thoughts and samples of these are displayed below. The themes were:

- Inability to access all the resources at work

- Only being able to view a resource once

- Time; waiting for others to join in tasks and occasionally lack of group involvement

- Time; coincided with summer holidays for some For example;

The tensions around group dynamics reflect issues which arise from time to time in all team working. Thus this aspect is not viewed as necessarily negative in use of such a tool. The feedback from the pilot participants particularly around disliking being "made to choose" reflects UoN experience with students (Westwater-Wood \& Dennick, 2011). Individuals feel that they might be losing something or lack confidence to justify their clinical reasoning out loud to the multi-professional group. Again these decisions around optimising time by reasoning choices are a valuable experience for real practice. To have the opportunity to hear and present reasoning for these choices is core to reflective practice and developing expertise (Schon, 1991).

\section{Usability}

The ReTool was evaluated by users for usability. Nine of the twelve participants provided feedback and rated it positively with $88.9 \%$ agreeing that overall usability was easy or very easy (Table 2). This is in keeping with the UG pilot where overall usability was also rated highly (Westwater-Wood \& Dennick, 2011).

\section{AHPs New to Paediatrics}

As was discussed previously it was not possible nor felt entirely appropriate to only have AHPs who were new to paediatrics participating in this pilot. However it was essential to ascertain the appropriateness of the ReTool for AHPs who will be new to paediatrics.

Nine individuals responded to the questions about elements of task, facilitation, IPL and the discussion forum with results being very positive on a 5 point rating scale. With 5 being strongly agree (Table 3 ).

It was also important to consider whether the learning outcomes set for the pilot would meet the requirements of AHP's
Table 2.

ReTool usability ranking (N9).

\begin{tabular}{ccccc}
\hline Rating & $\begin{array}{c}\text { Overall } \\
\text { usability } \\
(\mathrm{n}=9)\end{array}$ & $\begin{array}{c}\text { Videos } \\
\text { usability } \\
(\mathrm{n}=9)\end{array}$ & $\begin{array}{c}\text { Audio } \\
\text { usability } \\
(\mathrm{n}=9)\end{array}$ & $\begin{array}{c}\text { Document } \\
\text { usability } \\
(\mathrm{n}=9)\end{array}$ \\
\hline Very difficult & $0 \%$ & $0 \%$ & $0 \%$ & $0 \%$ \\
Difficult & $0 \%$ & $0 \%$ & $11.1 \%$ & $0 \%$ \\
Acceptable & $11.1 \%$ & $11.1 \%$ & $0 \%$ & $0 \%$ \\
Easy & $77.8 \%$ & $55.6 \%$ & $44.4 \%$ & $44.4 \%$ \\
Very easy & $11.1 \%$ & $33.3 \%$ & $44.4 \%$ & $55.6 \%$ \\
\hline
\end{tabular}

Table 3.

Task, IPL elements and Learning outcome achievement.

\begin{tabular}{|c|c|}
\hline Task, IPL elements $(\mathrm{n}=9)$ & Mean \\
\hline The tasks are set at the right level & 4.00 \\
\hline Facilitation sessions are useful & 3.78 \\
\hline Tasks are a useful way to facilitate IPL & 4.00 \\
\hline $\begin{array}{l}\text { Discussion forum is a useful way to explore clinical } \\
\text { decision making }\end{array}$ & 3.67 \\
\hline Learning outcome $(\mathrm{n}=10)$ & Mean \\
\hline $\begin{array}{c}\text { Develop knowledge and understanding of a specific } \\
\text { paediatric pathology }\end{array}$ & 4.00 \\
\hline $\begin{array}{l}\text { Develop clinically provoked problem solving skills and } \\
\text { confidence mean }\end{array}$ & 3.40 \\
\hline $\begin{array}{c}\text { Develop clinical reasoning in regard to the management } \\
\text { of a paediatric condition }\end{array}$ & 3.60 \\
\hline
\end{tabular}

new to paediatrics. Ten individuals responded to this question with results being very positive (Table 3 ) again on a 5 point scale with 5 being strongly agree. The mean value has been used to report these findings (Bandolier, 2010).

\section{Inter-Professional Learning}

In working with children and young people a core skill is the ability to work as part of a multi-agency team, learning with and from each other. Individuals were therefore asked to comment on IPL as part of the pilot and also in general; ten individuals completed this section and rated the experience positively in this skill (Table 4).

The reflective reports elicited comments on the topic of IPL with a theme around valuing the opportunity to discuss with other professions for example:

"I felt that the multi-professional approach was useful in developing MDT working because, through the discussion forum decisions were reasoned by members of the group"

"Learned more about how OTs \& SLTs structure an assessment with a paediatric patient and what wording they use/don't so better able to communicate with them"

"Excellent forum for discussion with other health professionals-allowing for understanding of different approaches to treatment"

This appears to reflect the MDT demands of case management in paediatrics. It supports the notion that individuals want 
Table 4.

Use in IPL ( $\mathrm{n}=10)$.

\begin{tabular}{lc}
\hline Question & Mean \\
\hline $\begin{array}{l}\text { Useful to work with other health care professionals in a } \\
\text { group }\end{array}$ & 4.20 \\
$\begin{array}{l}\text { Gained knowledge about another professional during pilot } \\
\text { Learning in this way could facilitate joint working and }\end{array}$ & 3.40 \\
$\begin{array}{l}\text { decision making } \\
\text { Would prefer to work with uni-professional group }\end{array}$ & 3.50 \\
\hline
\end{tabular}

to learn together which is found within the literature around learning being facilitated with peers or near peers (Daniels, 1996; Evans \& Cuffe et al., 2009).

\section{Future Recommendation}

Finally the participants were asked whether they would recommend the ReTool as a learning resource. The results were overwhelmingly positive (Table 5).

\section{User identified Limitation}

Although this appears to be generally a very positive response to this pilot by participants a theme which emerged over several aspects and not one question was that the time required was more than expected with a need to be more directing in the level of commitment for all group members.

For example:

"the nature of the time commitment of the tool lends itself to those who are not facing the time pressures of a demanding job”

"I found it difficult working in the group and felt that not all members of the group were committed to the pilot"

\section{Discussion}

Although some participants highlighted the need to be more directive and to agree from the outset times and commitments to $\log$ in and to contribute to the discussions. Overall this was a minor theme. It may be explained by the period during which the project ran as unfortunately several individuals had holidays during this time. It might be that other group members could have summarised or provided an update of what had gone on in their absence. This is perhaps indicative of the need for AHPs to engage in more inter-professional learning to enhance cohesion around the learning experience as a team. MDT group learning should be a core learning component, such as in this project, of all teamwork. The more evident positive perceptions of the experience were around opportunities to develop MDT communication skills and understanding of professional roles stimulated by the ReTool driving discussion around choices and justifying individual reasoning.

Some aspects not captured by the participant evaluation but noted by the facilitator and project team were the need to use terminology that was applicable for all AHPs or have a glossary of terminology e.g. subjective and objective assessment was not a term that SLTs used. It was also noted that there needed to be more attention to the regionalist nature of policies, legislation and agencies available to enhance an individual's learning. For example some content was England and Wales specific with
Table 5.

For what would the ReTool be recommended $(n=9)$.

\begin{tabular}{ccc}
\hline Prompt & Yes \% & No \% \\
\hline Experienced AHPs new to paediatrics & $100 \%$ & \\
Students on placement & $70 \%$ & $30 \%$ \\
New graduates & $90 \%$ & $10 \%$ \\
Returners to paediatrics & $77.8 \%$ & $22.2 \%$ \\
$\begin{array}{c}\text { Returners who have not previously worked } \\
\text { in paediatrics }\end{array}$ & $90 \%$ & $10 \%$ \\
\hline
\end{tabular}

some referenced services not in existence in Scotland i.e. Scotland has a visiting teacher service rather than Portage.

For the pilot it was important for participants to have internet access at home because of the inability to access the multimedia resources through the NHS firewall. Although this was acceptable for a pilot it would be a major area that would need addressed going forward. Otherwise there could be issues around equality and diversity if individuals could not access a key induction resource. Other platforms and the potential for any NHS closed system to have a parallel system for educational content isolated from the required very robust firewalls for patient content are options.

The feedback from the participants regarding choice and IPL are very important. The need to articulate clinical reasoning as part of a team is challenging and was integral in the conception of the development of ReTool; and the findings are supported in the literature and previous evaluations of the UoN UG programme. However, the strength in the ReTool format is that not only does it enhance IPL but because individuals need to compile a profession specific report they are also learning uni-professional elements. Both of these factors were identified in the NES 2009 scoping report as being essential in the development of a core resource for AHPs working within paediatric services.

Although there was some debate about the length of time the programme should be accessed over in general $4-6$ weeks is probably the preferred length. This gives individuals time to absorb and consolidate learning, to access reading materials relevant to the case studies and to analyse and discuss these. In a recent study conducted in NHS Scotland (unpublished) clinicians reported that once in practice they lost skills in being able to access evidence and critically appraise it. The wide literature on implementing evidence based practice echoes a gap between published literature and implementation, which is similar to these AHP clinicians experience (Haynes \& Haines, 1998; Restas, 2000; Schreiber \& Stern, 2005,). The nature of ReTool enables clinicians to maintain these skills in a safe environment with support of peer IP colleagues. This pilot users experiences are in step with the recommendations from the systematic review by Barr et al. (2005) in that they are positive, are collaborative and support development of capability.

\section{Limitations}

The main limitation of this pilot is the lack of long term follow up. Occasions of inter-professional discussion, any changes in amount or use of MDT goals, intervention program and support of AHP recommendations might be considered in an audit cycle. AHPs' own perceptions of changes in their own 
clinical practice would also be appropriate to consider in any further investigation.

\section{Conclusion}

The collaboration between UoN and NHS Education Scotland has been very positive. The contextualised e-tool program ReTool was successfully implemented and evaluated for the needs of inter-professional professional development in the field of paediatrics. Clinical reasoning and solution options from different AHPs were shared within multi professional groups and demonstrated the low desire for paediatric AHPs to work in uni-professional groups but to be aware of the balance in the size of larger groups and the dynamics therein. The ReTool should be incorporated into the induction component of the education framework for AHPs working with children and young people. To achieve this, the issues identified around glossary, referencing and learning relating to the needs of AHPs in Scotland and the barrier of the NHS firewall need to be considered. In addition to meeting the learning needs of individual's access to ReTool will also provide evidence for individuals to meet the requirements of the NHS Knowledge and Skills framework (Department of Health, 2004).

\section{REFERENCES}

Bandolier: Evidence Based Thinking about Healthcare (2010). Mean, median, mode. URL (last checked 22 September 2010).

http://www.medicine.ox.ac.uk/bandolier/booth/glossary/mean
Barr, H., Koppel, I., Reeves, S., Hammick, M., \& Freeth, D. (2005) Effective inter-professional education: Argument, assumption and evidence. Oxford: Blackwell. doi:10.1002/9780470776445

Daniels, H. (Ed.) (1996). An introduction to Vygotsky. London: Routledge.

Department of Health (2004). The NHS Knowledge and Skills Framework (NHS KSF) and the development review process. http://www.dh.gov.uk/en/Publicationsandstatistics/Publications/Publi cationsPolicyAndGuidance/DH_4090843

Evans, D. J., \& Cuffe, T. (2009) Near-peer teaching in anatomy: An approach for deeper learning. Anatomical Sciences Education, 2, 227-233.

Haynes, B., \& Haines, A. (1998). Barriers and bridges to evidence based clinical practice. British Medical Journal, 317, 273-276.

Restas, A. (2000). Barriers to using research evidence in nursing practice. Journal of Advanced Nursing, 31, 599-606. doi:10.1046/j.1365-2648.2000.01315.x

Schon, D. A. (1991). The reflective practitioner: How professionals think in action. Aldershot: Ashgate Publishing Ltd.

Schreiber, J., \& Stern, P. (2005). A review of the literature on evidence-based practice in physical therapy. The Internet Journal of Allied Health Sciences and Practice, 3, 1-10. URL (last checked 20 August 2012). http://ijahsp.nova.edu/articles/vol3num4/schreiber.pdf

NHS Education for Scotland (2009). Allied health professionals educational scoping exercise- - Initial findings.

http://www.knowledge.scot.nhs.uk/child-services/communities-of-pr actice/ahp-cyp-network/the-children's-chapter/references.aspx

Westwater-Wood, S., \& Dennick, R. (2011). A reusable e-learning tool for paediatric physiotherapy education: A preliminary report. International Journal of Medical Education, 2, 80-86. doi:10.5116/ijme.4e5c.942c 